\title{
Organization of Educational Process for Students of Humanitarian and Electrical Engineering Majors on Basis of Moodle Environment
}

\author{
Diliara Iakovets $^{1, *}$, Yulia Kusnetsova $^{1}$, and Rustem Zainutdinov ${ }^{2}$ \\ ${ }^{1}$ Department of Psychology, Astrakhan State University, 20A Tatishcheva St., 414056 Astrakhan, Russia, dl.sun75@gmail.com, \\ yuk80@mail.ru \\ ${ }^{2}$ Department of Physics and Technology, Astrakhan State University, 20A Tatishcheva St. 414056 Astrakhan, Russia, \\ $\underline{\text { rzain30@gmail.com }}$
}

\begin{abstract}
The authors of the article draw attention to the relevance of the use of e-learning tools to improve the quality of student preparation, as well as they consider the specifics of pedagogical communication within the framework of the information and educational environment. The language of education changes: there is a transition from written forms to audiovisual ones. In addition to traditional actors of the educational process (a teacher and a student), the third actor appears. It is learning tools that operate on the basis of information and communication technologies. The use of elearning resources in the learning process allows to provide flexible forms of students' interaction with a teacher and educational content; to organize interactive learning, follow-up and final assessment; to facilitate the management of the educational process for a teacher. The combination of in-class and online (extramural) forms of attendance is most effective. Also, it is necessary to include a cooperative learning approach in the e-learning model. The article describes the experience of using the virtual learning environment (Moodle) in organization of the educational process in a number of subjects ("Psychology of Lying", "Ergonomics", etc.) for the students of humanitarian and electrical engineering majors.
\end{abstract}

\section{Introduction}

Currently, due to the transition to the information society, the most important trend in the modern world development is a growing role of education. The principle of "education for life" is replaced by the principle of "lifelong education". This is necessary to adapt to constant and increasingly obvious changes in professional and social spheres. Now you can not severely divide the life trajectory into three periods:

- the school period;

- the period of professional activity;

- the retirement age.

Education received during the early life stages is not sufficient due to the rapid knowledge development, due to a huge amount of information obtained to a great extent thanks to new technologies, as well as due to the new competencies required in the work market $[1,2,3]$.

Thus, there is a need for a modern person in constant improving his/her information culture, as well as in constant learning for successful professional selfrealization and effective integration into society. In these conditions, new requirements are imposed on the system of education and on learning tools [2].
One of the priority directions of the education development is the implementation of information and communication technologies into the learning process. Electronic technologies expand educational opportunities and open new approaches to learning [4].

Modern pedagogical practice offers e-learning as a system providing the intensification of the learning process and exchange of information, as well as the individualization of the educational content [1].

The potential of new technologies lies in their ability to act as a common network and simultaneously it has an opportunity to carry out both individual and cooperative learning.

This determines the urgency of using information and communication technologies to improve the quality of students' fundamental learning at the university.

New educational standards of higher education in the Russian Federation presuppose the formation of an electronic information and educational environment within educational institutions. Public web services and educational resources together with internal resources of an educational institution become an effective mechanism for the development of the e-learning environment. The teacher acquires additional opportunities for a creative approach to the organization of the learning process, the organization of educational cooperation, the attraction of

*Corresponding author: dl_sun@mail.ru 
students to the development of the electronic information and educational environment. The teacher can transform students' learning activity from a reproductive form into a productive, personified form.

The organization of this kind of educational activity contributes to the development of professional competencies of modern professionals [5].

The use of information and communication technologies by a teacher becomes a conscious necessity in the organization of the learning process.

\section{Characteristics of educational discourse within the information and educational environment}

The educational process of the university contains various components including educational discourse as a system of linguistic (a text and a speech) and extralinguistic (goals, opinions, orientations, knowledge about the world) factors. Consideration of extralinguistic factors is necessary for understanding the text.

In the broadest sense, discourse is a sequence of communicative acts performed in the language: a dialogue, written texts related to one topic, etc.

Educational discourse is one of the types of institutional discourse and it represents communication within status and role relationships. Mainly, along with the educational goal, its goal has three component:

- professional field;

- public life;

- personal sphere.

The professional field includes the participants' key competencies formation in the educational process; the public life represents a full-fledged socialization of an individual in society; and there is a formation of a selfvaluable personality in the personal sphere [6].

Educational discourse has a number of systematically important characteristics:

- it is organized within a certain social institution (educational institution);

- it is characterized by the participants' status and role relationships in communication (a teacher and a student);

- it has a purpose;

- in content, it is learner-centered (purpose, methods and means are related to the development of the learner's personality in the organized process of social education).

Today, in the conditions of a snowballing growth in the amount of knowledge, it is important to move from the academic presentation of content to building "living knowledge" and it is important to teach learning. This is the most important condition for the effectiveness of educational discourse, an indicator of its humanitarian quality [6].

The peculiarity of educational discourse in traditional form of education is the status inequality of its participants. The very essence of the teaching profession imposes a monopoly on communication.

Learning with the use of online educational resources has its own specificity of communication, its specificity of communication between a teacher and a student.
The language of learning changes: there is a transition from written forms to audiovisual ones.

In a certain sense, there is a crisis of the teacher's role: he or she loses the role of knowledge transmitter. The student's role also changes. He or she became an active participant in the educational process from a passive object of learning. The actors of the educational process become more equal; the student is potentially more independent from the teacher [3].

Such a change in the nature of communication causes fear of losing control over the learning process among some teachers.

I.V. Robert highlights an interesting feature of information interaction within the information and educational environment. He speaks about the emergence of a third actor in the educational process, namely a learning tool functioning on the basis of information and communication technologies (see Fig. 1). In our case, it is a virtual learning environment Moodle.

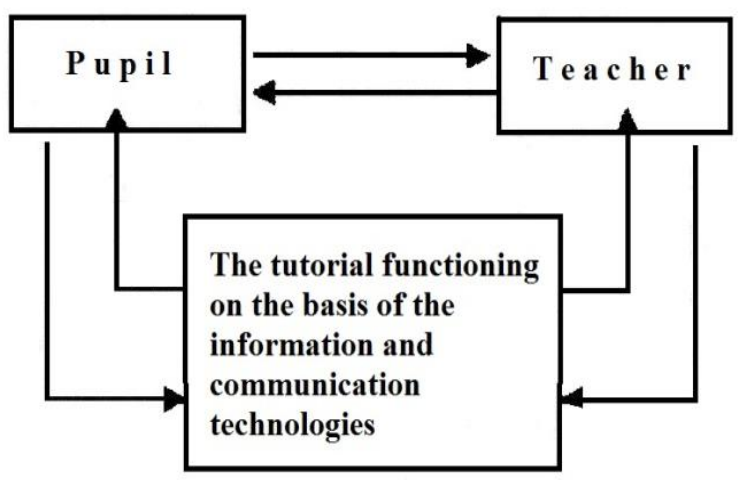

Fig. 1. Information interaction within the information and educational environment

In this scheme of information interaction, the activity is possible both on the part of a learner and a teacher, and also on the part of a learning tool.

The activity on the part of a learning tool is possible due to:

- ensuring prompt feedback between a user and means of information and communication;

- computer visualization of educational information;

- easy access to distributed information resources;

- automation processes of computing, informationretrieval activity, operations for collecting, processing, transferring and replicating information, archiving large volumes of information;

- automation processes of information and methodical, organizational management of learning activity and control over the results and progress of learning.

Thus, a part of the teacher's functions is transferred to a learning tool functioning on the basis of information and communication technologies.

In this scheme the student has the conditions for independent development of educational topics corresponding to an individual programme, the conditions for choosing the direction of further advancement in learning. At the same time the teacher fulfills the role of 
curator, in a certain sense of a "navigator" in the information and educational environment on the way of mastering knowledge [3].

Another peculiarity of pedagogical communication within the information and education environment is interactivity. It is one of the information and communication technologies advantages in education. Interactivity comes out in immediate feedback, in diverse and intensive communication between all participants of the educational process.

The large volume of knowledge leads to a crisis of study programmes and brings up an issue of a course content.

Information and communication technologies provide with flexible forms of interaction between students, teachers and training materials. A teacher can set an appropriate form of presentation and consistency of the material delivery and use the same material for different categories of students.

E-learning with mass open courses is often introduced in order to avoid the necessity of physical presence at a certain place (which we have in case of offline learning). However, the percentage of students' dropout is high. One also has to be very self-disciplined in order to study online [7]. Introducing freedom and flexibility to the educational process, Internet requires a responsible approach, real intrinsic motivation to study and self-discipline in terms of deadlines and requirements.

The paper [7] proposes to limit the access to and repetition of online courses in order to reduce students' dropout (on the basis of the psychological reactance theory). These measures arise sensation of control limitedness, which, according to the authors, can increase students' memory concentration and stimulate their intention of taking online courses further on and in a more detailed way.

As mentioned above, the information and communication technologies development has led to evolution of e-learning and respective educational technologies, which means more communication and cooperation. The information and communication technologies breakthrough has changed the world and contributed in a more social approach to education. However, e-learning usually implies an individualistic approach, takes place in an isolated area, under conditions of weak involvement of students in a teamwork. It is not enough to pay attention only to the content and technology - an e-learning model needs a cooperative learning approach $[1,2]$.

So, it is necessary to introduce "cooperative learning". It can be in a form of [1]:

- interaction between a teacher and students;

- interaction between students;

- interaction with content;

- interaction with oneself (i.e. self-reflection).

\section{Experience in application of the virtual learning environment "moodle" in organizing educational process for}

\section{students of humanitarian and electrical engineering majors.}

Astrakhan State University is currently implementing study programmes with information and communication technologies elements by means of an information and education environment based on Moodle, a platform of virtual learning environment (learning management system). Several subjects of the Astrakhan State University Chairs of Conflict Studies \& Organizational Psychology and Electrical Engineering, Electronics, \& Automatics are taught through this information and education environment, including such subjects as "Psychology of Lying" and "Ergonomics".

No matter where they are, students are given a 24hour access to the courses training materials (lectures, etc.) and different tasks to complete online with the use of such Moodle tools as surveys (questionnaires), databases, tests, seminars, forums, wiki pages and chats.

The paper [8] presents assessment of opportunities of using Moodle in educational institutions. Moodle is usually used for presenting a study course content, a plan of its completion, creation of different events, feedback collection and communication with the course participants.

In regard to this, our courses include such elements as modules of practical tasks, feedback, surveys, assignment of events (forums, chats).

According to J. Derboven et al., few teachers study opportunities of learning environments in full; almost all trainers use a limited set of available tools. There are too many means for creating certain types of training materials, and it is necessary to expand the range of communication means [9].

The virtual learning environment of the learning management system "Moodle" supports such e-learning services (related to users' communication) as emailing, direct messages, forums, data collection and record, plagiarism check, students' papers review and assessment, surveys and questionnaires. In addition, information transfer from a student to a teacher (completed tasks, comments, received marks, etc.) becomes significantly faster because Moodle contains all communications of the course in one place.

Feedback plays an important role in e-learning systems $[10,11]$.

In learning management systems, marks are often separated from teachers' feedback by default. Students are unlikely to read feedback when they see their marks separately. It will be better if, in order to learn his/her marks, a student has to download an attached file with feedback [11].

The paper [12] presents a comparative analysis of forums and wiki pages as tools for interactive online learning. It was found out that forums are used for discussions and exchange of ideas, while wiki pages serve a tool for joint drafting of a document. The main processes at forums are organization, proposal, support and assessment of different discussions, and wiki pages are concentrated on production and development processes. Time needed for these activities is also different - it is 
easier to get access to forums, while it takes much time to work with wiki pages and they are more difficult to use.

It is impossible to talk about advantages of one activity over the other. Each of them has its own features and can be used for different purposes. It is necessary to organize them in a supplementary way for self-control learning strategies.

Our developed courses involve both tools. In particular, the Ergonomics course includes the usage of forums to discuss presentations and papers prepared by students themselves. As for wiki pages, they are used to work on a group project on a specific topic. The course "Psychology of Lying" contains a task on revealing a lie in a literary fragment using wiki pages.

Teachers practise three ways of self-expression through Moodle:

- in written form;

- $\quad$ using the interface;

- $\quad$ through the content (the course content) [13].

Students also mark out these ways of self-expression. A teacher is present at and recognized through the interface [13].

Homework assignment is a labour-intensive and timeconsuming process. Online homework has shown itself to good advantage. A survey, held among students on their preferences for offline or online homework, showed that they prefer online tasks [14].

The developed courses include homework in a form of online tests.

These courses are widely used within students' selfstudies. Nowadays, issues of self-studies organization are especially urgent, as the number of in-class hours is decreasing, while students are required to receive more knowledge.

Communication between a teacher and a student fails in a lack of live contact, which impedes students' personal growth $[1,2]$. This problem can be solved by holding virtual classes, and such experience is described in [15]. In one of the Astrakhan State University branches, they organized lectures and practical classes on Ergonomics with two-way videoconference communication.

The videoconference communication allowed the teacher to be present at the lesson, provided with personal contact and an opportunity for the students to asks questions and receive answers immediately; the teacher could estimate the level of the material comprehension without doing tests. The students were involved into the educational process. The final test was conducted in presence when the teacher visited the branch.

\section{Conclusion}

The application of e-learning resources in the educational process allows one to:

- provide with flexible forms of interaction between students, teachers and study materials;

- organize interactive learning;

- organize follow-up and final assessment;

- facilitate educational process management for a teacher.
By delivering a part of the material virtually, a teacher acquires additional opportunities for a creative approach in educational process organization. Introduction of information and communication technologies to the educational process makes it free from the necessity to deliver a large volume of conceptual information but requires preliminary work on tasks and situations, as well as individual work with students and the educational process monitoring.

Combination of in-class and online (extramural) forms of studies appears to be the most efficient.

It is also necessary to include cooperative learning in the e-learning model.

The authors keep on working on development of elearning resources for other subjects taught by them at the university.

\section{References}

1. H.Haron, N.H. Natrah, A.A. Harun, Proc. Computer Science 116 242-250 (2017)

2. K. Markov, IJ Information Technologies and Knowledge 4(4), 373-396 (2010)

3. I. Robert, Theory and technique of informatization education (psychology-pedagogical and technological aspects) (Moscow. Institute of informatization of education of the Russian Academy of Education, 2008)

4. F. Moreira, C.S. Pereira, N. Durão, M.J. Ferreira, Telematics and Informatis 35(4), 979-992, (2018)

5. I. Golitsyna, Procedia - Social and Behavioral Sciences 237, 939-944 (2017)

6. D. Goncharova, Topical issues of linguistics and a technique of teaching a foreign language in the system of pre-university and high school preparation: materials of the Second scientific and methodical conference, 23-27, (2012)

7. T. Kim, M. Yang, J. Bae, I. Lee, J. Kim, Computers in Human Behavior 66, 217-231 (2017)

8. D. Kc, Proc. Computer Science 116, 121-128, (2017)

9. J. Derboven, D. Geerts, D. Grooff, Journal of Visual Languages \& Computing 40, 20-35 (2017)

10. B.A. Abu, W.T. Tengku, N.S. Ashaari, International Conference on Electrical Engineering and Informatics, 633-637 (2015)

11. A. Laflen, M. Smith, Assessing Writing 31, 39-52 (2017)

12. Biasutti, Computers \& Education 111, 158-171 (2017)

13. L.S. Espindola, M.S. Silveira, Journal of Visual Languages \& Computing 40, 36-50 (2017)

14. A.L. Elias, D.G. Elliott, J.A. Elliot, Education for Chemical Engineers 21, 40-49 (2017)

15. L. Zaynutdinova, M. Pol'sky, D. Iakovetc, Creativity pedagogics: personality, knowledge, culture: Materials of the International scientific, 284-288, (2017) 